\title{
Ethics and Christology - Rediscovering Jesus in Evolutionary History
}

\author{
$\mathrm{J} \mathrm{W}_{\text {van Huyssteen }}{ }^{1}$ \\ (Princeton Theological Seminary, U S A)
}

\section{ABSTRACT \\ Ethics and Christology - Rediscovering Jesus in Evolutionary History}

The rather perplexing issue of whether and how Christology should relate to Ethics can, for me at least, only be resolved by first asking how exactly, in the case of Jesus, God's revelation is located not just in history, but specifically in evolutionary history itself. The evolutionary history of our species, as well as those characteristics that we normally see as defining the distinctiveness of Homo sapiens (consciousness, imagination, moral awareness, religious propensities, etc.) should not only directly impact notions of our own embodied personhood, but also what it would mean to understand Jesus' embodied mind, his consciousness and self-awareness, as defining his personhood. In this sense a focus on the identity of Jesus will shape the ethical relevance of who He was, what He did, what He said, and why we today might feel compelled to follow that example.

\section{INTRODUCTION}

If next we find in ancient doctrine a hermeneutical starting point for thinking about Jesus as 'fully human and fully divine', then the sheer fact of his complete humanness should also be a (biblical) key to understanding his imaging of God as an embodied male who share with us our most defining human characteristics precisely as they evolved evolutionary history. Furthermore, in a postfoundationalist approach to the problem of Christology and Ethics, the challenge at hand definition becomes an interdisciplinary problem: if Jesus was, like we are, deeply embedded in evolutionary history, what might the sciences tell us today about the evolution of our most uniquely human characteristics, our consciousness, self-awareness, linguistic capacities, religious propensities, embodied imagination and sexuality, and most importantly, the evolution of our moral

1 Research associate, Prof J C Müller, Department of Practical Theology, University of Pretoria. 
sensibilities? And how might the evolution of these uniquely human characteristics help us understand better who Jesus was, and therefore, where his moral authority came from, and whether, and why, that should matter for our ethics?

Against this background, for me at least, any theological discussion of Christology and Ethics should start with an interdisciplinary conversation with the sciences and philosophy on what we are learning today about the evolution of consciousness and morality. Both methodologically and substantially this seems to yield the necessary building blocks for revealing first, an evolutionary link between Christology and Ethics, and second, a theological link between Christology and Ethics. Thanks to contemporary primatology, paleoanthropology, and also the neurosciences, we know today that the embodied human mind has a capacity for moral awareness, an innate sense for 'right and wrong' that is embedded in deep evolutionary history. How much, in the case of Jesus of Nazareth, should we speculate about his evolved sense or right and wrong, and would a theological perception of 'divine nature' add anything to why Jesus Christ (and the way we construct our Christologies) may be important today for ethics? Ultimately I will argue that viewing our Christologies less as foundationalist frameworks, and more as epistemic pointers for a constructive interdisciplinary theology, creates a space for both an awareness of mystery in Christology, as well as discerning reasons why 'we should do what Jesus did'.

My argument will unfold by asking two key questions: first, what do we learn from evolutionary history about the evolution of morality and moral awareness in humans? And, second, what do we learn from evolutionary history about the way we construct our moral codes and our ethical systems? Answering these two questions will enable me to pose two final questions: first, are there plausible links that might be explored between the person of Jesus and the evolution of human cognition? And second, might there be evolutionary and theological reasons why what Jesus said and did are normative for us today as we construct our moral codes and ethical norms?

\section{ETHICS AND EPISTEMOLOGY}

From evolutionary epistemology we learn that evolution turns out to be about much more than the 'origin of species' and is instead a 
much richer cognition process that shaped the way our embodied minds work, how our bodies communicate, and how we know the world. As such, evolutionary epistemology highlights both the deeply embodied, as well as the fallibilist nature of all human knowledge, and explains that there are advances and growth in human knowledge, but that this 'progress' is not necessarily an increase in the accuracy of depiction, or an increase in the certainty of what we know. This view is strengthened by the conviction that for evolutionary epistemologists self-conscious human cognition is a bridge between biology and culture, or rather, integrates biology and culture, biological evolution and cultural evolution. Evolutionary epistemology also reveals that we humans can indeed take on cognitive goals and moral ideals that cannot be explained or justified in terms of survival-promotion or reproductive advantage only. Therefore, once capacities for rational knowledge, moral sensibility, aesthetic appreciation, and the propensity for religious belief have emerged in our biological history, they cannot be explained only in biological/evolutionary terms any more. In this sense we clearly transcend our biological origins and do have the ability to transcend what is given to us both in biology and culture.

This implies a quite specific relationship between evolutionary epistemology and evolutionary ethics: evolutionary ethics, as primatologists like Frans de Waal (2006), and moral philosophers like John Hare (2004) argue, clearly reveals the biological reasons for the evolution of moral awareness, but this does not yet lead to an evolutionary explanation for the formulation of specific moral codes, laws, or norms. Evolutionary ethics can only help us reconstruct the preconditions for moral behaviour but says nothing about the validity of certain norms that have developed in cultural evolution and are thus constrained by sociocultural conventions. This is the reason why there may be different rationales inherent in different sociocultural systems, and why different cultural contexts may lead to different moral codes.

Evolutionary epistemology thus provocatively reveals what happens as, both epistemically and morally, we make our way through our highly contextualised worlds. It is especially interesting to look at this through a Kantian perspective. Immanuel Kant argued that it is our minds that order our sensations, and that we possess some knowledge a priori independent of these perceptions. But Kant did not tell us why our sensations are ordered by our minds as they 
are and not otherwise; nor did he tell us anything about the origins of this mental power. From an evolutionary point of view any a priori knowledge is the result of evolutionary experiences, of evolutionary learning. And in this sense what is seen as an individual's a priori is in fact revealed as an evolutionary aposteriori, namely, that what has been interactively learned from experience over time. In this way evolutionary epistemology offers a dynamisation and a historisation of the Kantian categories and as such goes far beyond Kant's philosophy (Wuketits 1990:185).

What now becomes clear is that ethical behaviour is indeed a product of our biological evolution but this fact by itself does not entail any normative assertions: from the fact that morality has developed we cannot conclude that any particular trait of human behaviour is good or bad (right or wrong) in an ethical sense. Put differently, an evolutionary account of ethics does not support any specific moral code, but it may help us understand why such codes have developed (Wuketits 1990:202). We should therefore be careful to always distinguish between the evolution of moral awareness, and the evolutionary justification of moral codes. Evolutionary ethics in this second sense has a bad history and has resulted in ideologies like Social Darwinism.

When I use the term evolutionary ethics I use it to characterise the view that morality has evolved and there clearly are biological roots for moral behaviour. However, from the evolutionary genesis of our moral awareness we cannot easily derive what is right or wrong. Accepting that our moral awareness has evolved also means accepting that our moral codes may not be fixed forever as unchangeable entities. We humans are therefore free to find our own moral goals in this world, and an evolutionary approach to ethics and morality helps us understand under which circumstances humans have created what kinds of values and moral codes. In an evolutionary approach to ethics the creation of moral norms, in an aposteriori sense (to use Kantian terms), will be found to lie on a constructive, cultural level. This of course means that humans in principle are free to change their moral codes, but this also means that we humans carry great responsibility for our own behaviour and that this responsibility cannot, and should not, easily be delegated to 'objective divine moral codes' (in this sense even iconic moral codes like the Ten Commandments and Jesus' love command, over time, are revealed as aposteriori moral laws). This also frees us from the 
foundationalist need for an idea of absolute moral truth: our idea of truth is relative to our historical and social contexts and their histories, and only a coherentist, postfoundationalist approach can sufficiently explain this.

What evolutionary epistemology finally gives us is the open view of evolution: basic patterns of our behaviour depend on, and have been developed through, our evolutionary past. But this is not a determinist view. As higher organisms we are capable of learning so that even evolutionary programs may be modified (Wuketits 1990:207). Appreciating this ethological fact and appreciating the human brain's plasticity, this leads us to a nondeterministic view of human nature: we humans have the responsibility to make our own decisions on the norms and limits to our own behaviour. We ourselves are responsible for our actions in the world. We are, therefore, constrained, but not determined by our evolutionary past.

\section{FINDING A BRIDGE BETWEEN ETHICS AND CHRIS- TOLOGY}

The two crucial, distinct questions that I want to address in this paper can now be rephrased as follows: taking into account the deep history of the evolution of hominids and humans, does the theory of (human) evolution help us answer the following two questions i) can we be morally good? And, ii) why should we be morally good? John Hare has argued that we do not get answers to these questions from the theory of evolution (Hare 2004:187). I will now argue, however, that the theory of evolution does indeed help us to answer the first, but not the second question. Dealing with these two distinct questions will help us to answer broader inquiries like whether we can indeed find an evolutionary basis for human morality, and if so, whether evolutionary ethics might enable us to find an interdisciplinary, transversal connection to theology, and ultimately even to Christology.

In the final part of this paper I turn to the question of Christology and Ethics and ask what kind of, or what model of Christology might converge with this interdisciplinary conversation with evolutionary epistemology and evolutionary ethics, and how might it help us unveil important evolutionary as well as theological links between Christology and Ethics. Against this background I will then to turn to the thought of Friedrich Schleiermacher. I believe that, in spite of the weight of history and historical controversies, 
Schleiermacher still gives us significant, if not surprising epistemological pointers to deal with these issues, even a very contemporary issue like Christology, ethics, and evolution. In The Christian Faith, Schleiermacher already argued in a remarkably contemporary and evolutionary way that the physical aspects of our human existence not only preceded, but also provided the basis for what later evolved as our capacity for spirituality and faith in God. In this sense he posits that in the long evolution of humanity, our physicality involved a necessary self-preservation instinct that led to a protection of one's own self and kind over against that which was defined as other (Suchoki 1999:88). This mode of self-centeredness served well to insure the survival of the human species, but Schleiermacher clearly sees our 'physical beginnings' as existing and necessary for the sake of that which would later emerge from physical existence, namely, the God-consciousness of human spirituality.

It is fascinating to remember, especially in the light of the sharp focus today on consciousness in the neurosciences, that Schleiermacher already famously distinguished between three grades or levels of self-consciousness: first, the confused animal grade of consciousness; second what he called 'the sensible consciousness'; and three, the feeling of absolute dependence. These three grades are structured developmentally, with the second arising from the first, and the third from the second. As finite human beings we primarily experience the second grade, which is structured as a tension between feelings of freedom and dependence. For Schleiermacher the 'actual occurrence' of human self-consciousness is never separated from the lower grade of animal consciousness and as such it always "participates in the antithesis of the pleasant and the unpleasant" (Schleiermacher 1976:18). Schleiermacher does say (in a sentence that Charles Darwin would have loved), "that the animal state is to us really entirely strange and unknown. But there is general agreement that, on the one hand, the lower animals have no knowledge, properly so called, not any full self-consciousness which combines the different moments into a stable unity, and that, on the other hand, they are nevertheless not entirely devoid of consciousness" (Schleiermacher 1976:18). The origins of typically human, second grade 'sensible self-consciousness' can, therefore, clearly be found in the earliest humans: "If we go back to the first obscure period of the life of man, we find there, all over, the animal 
life almost solely predominating, and the spiritual life as yet entirely in the background; and so we must regard the state of his consciousness as closely akin to that of the lower animals" (Schleiermacher 1976:18).

When the sensible self-consciousness has 'expelled the animal confusion', then there is disclosed a higher tendency, and the expression of this tendency in this level of self-consciousness is the 'feeling of absolute dependence' (Schleiermacher 1976:22). And this feeling of absolute dependence, so characteristic of the third level of consciousness, is equivalent to our being conscious of being in relation to God. Here self-consciousness becomes Godconsciousness, in which our finitude is not transcended but put into proper perspective. In this sense to feel oneself absolutely dependent and to be conscious of being in relation with God is one and the same thing. In this sense also self-consciousness cannot be separated from God-consciousness, and the feeling of absolute dependence becomes a clear self-consciousness in such a way that the two cannot be separated from one another. In this sense it can be said that God is given to us in feeling in an original way, and "if we speak of an original revelation of God to man or in man, the meaning will always be just this, that, along with the absolute dependence which characterizes man... and all temporal existence, there is given to man also the immediate self-consciousness of it, which becomes a consciousness of God" (Schleiermacher 1976:17f.).

Schleiermacher also points to what we today would call a 'biological basis for sin', and the human predicament is precisely that our nascent spirituality is much weaker that the longestablished, evolutionary selfishness (cf. Suchoki 1999:89). For Schleiermacher this problem of original sin is resolved by God's own interjections into creation through incarnation in the form of the Redeemer. This Redeemer, being of God, is capable of that which the rest of humanity so sorely fails. But also being human, the Redeemer fits into the interconnectedness of all finite existence, so that what the Redeemer accomplishes becomes a fact of existence that affects us all deeply (Suchoki 1999:89). And the Redeemer, who is God incarnate in Jesus of Nazareth, lives in perfect Godconsciousness, proclaims that consciousness and passes it on to the rest of humanity. In Jesus of Nazareth, then, the world achieves its completion, and humanity achieves its release from its imprisoning sin. 
The question, of course, is whether Schleiermacher's remarkable convergence with contemporary evolutionary theory necessarily will lead to a 'low Christology' where evolutionary history is taken seriously, but Jesus becomes only a moral exemplar or symbol? In an intriguing essay, Kevin Hector (2006) has argued the exact opposite. Hector argues that any attempt to define Schleiermacher's Christology as 'low' would be seriously inadequate because it would neglect the important role that actualism plays in his theology. Actualism here refers to a deeply relational (I would say, embodied) way of thinking that focuses on the dynamics of events and relationships (Hector 2006:307). Through correctly understanding the dynamism of Jesus' relationship to God, it became possible for Schleiermacher to see Christ as the one who reproduces God's pure act of love through his own intense God-consciousness. In this way Jesus exists as deeply embedded in embodied, relational activity and so, for Schleiermacher, is God truly incarnate. On this view, therefore, Schleiermacher's Christology is not 'low' at all, but in fact quite 'high' - in some respects even higher than traditional Chalcedonianism (Hector 2006:308), if we mean by 'high' the unequivocal recognition that Jesus the man is God incarnate, and that he is uniquely so. In addition, Schleiermacher's graded notion of consciousness offers an intriguing parallel trajectory to positions in contemporary evolutionary biology and neuroscience.

Kevin Hector thus very much argues against the fairly customary reading of Schleiermacher as denying Christ's full divinity, compromising his humanity, and thus seeing Christ as the most exalted of humans, but not as truly divine. Moreover, we now know Jesus through our fellowship with him, and in this fellowship, we are drawn out of our previous sinfulness and into blessedness. However, this drawing-out cannot be explained in terms of normal human history, because everyone in that history participates in corporate sinfulness. The possibility of this happening must then come from 'outside' history, and it must come in such a way that its activity depends solely on its outside impulse (Hector 2006:310). This possibility does not remain outside of history, however, as we know from the fact that it has become our possibility too: in Jesus Christ, this possibility enters into history and thereby becomes ours. Hence, when we examine our experience of Christ, we see that we cannot explain Christ merely in terms of normal human history. And 
this is what Schleiermacher meant when he concluded that Christ must be God incarnate, because this alone explains the fact that his life is the pure, relational act that establishes fellowship between us and God (Hector 2006:310).

The very identity of the person of Jesus Christ is thus tied up in the spiritual function of the God-consciousness that is one with his self-consciousness. And again, to ascribe to Christ an absolutely powerful God-consciousness, and to attribute to him an existence of God in him, is exactly the same thing. Jesus is the only 'other' in which there is an existence of God in the proper sense (cf. Schleiermacher 1976:387). But as a person of this kind he needs to have the whole of human development in common with us, so that even this existence of God must in Him have had a development in time. If God is a God of love, and if God's relational activity can only be described as pure love, then Christ too is the pure act of love, of unifying God's love with us. For Hector this is exactly what Schleiermacher asserts: Jesus is the One who reproduces God's pure, loving act in human history, and is therefore God incarnate. And the key to this divinity of Christ is his God-consciousness, which functions as the relational medium by which God's love is apprehended and turned into Christ's own activity (Hector 2006:311). Christ's God-consciousness is, on this view, that which makes it possible for God to become incarnate in a human. This is not the same as our general, human, 'innate' God-consciousness, which of course is presupposed in our faith in God and Jesus Christ. But Christ is the only creature in whom the God-consciousness in him was absolutely clear and determined each moment, to the exclusion of all else, so that it must be regarded as a continual living presence, and a real existence of God in him (Hector 2006:397).

Hector thus provides us with a plausible, alternative reading of Schleiermacher and correctly argues that 'perfect Godconsciousness' in Jesus Christ can be equated with 'divinity' precisely because Christ's God-consciousness is the human 'organ' through which God's activity becomes incarnate. The important thing about Jesus, then, is not his God-consciousness per se, but the fact that this consciousness is the means through which God's being is incarnated. In this way it is clear that Schleiermacher offers us a relational, non-essentialist picture of God as the pure activity of love, of Jesus as the historical repetition of this activity, and of Jesus' work as a repetition of his person (Hector 2006:312; 322). 


\section{SHOULD WE DO WHAT JESUS DID?}

In the final part of my argument I want to link the question of Jesus' identity, and the follow-up question of why his words and deeds should have normative value for us, back to what we have gleaned earlier from evolutionary epistemology and evolutionary ethics about the evolution of moral awareness. There we saw that evolution yields, as it were, the moral sense but not specific codes for morality. So, if we take into account what we have learned about so-called $a$ priori accounts of knowledge or morality, our moral codes or 'laws' in the fullest sense of the word are aposteriori, that is, gleaned from interpreted experience. The choice is not, for instance, between a moral vision that is inherent in revelation and is, therefore, 'received' and not 'invented'. Instead, on a postfoundationalist viewpoint our moral codes and ethical convictions of what is 'received' is itself an interpretative enterprise, shaped experientially through our deep embeddedness in communities and cultures.

Therefore, our natural, inborn tendency to think normatively never leads to an evolutionary explanation for why any specific set of moral codes or moral laws are universally correct, or given in any strong sense of the word. Moral judgments, however, have 'practical clout' in terms of the formal, social, conventional ways we come to make moral judgments and decisions, and as such they make inescapable and authoritative demands on us (Joyce 2006:57-64). But whatever authoritative demand or practical clout moral judgments, codes, or laws, may have on us, it does not find its source in a choice between external/eternal or internal/evolutionary sanctions, but rather in human convention and discernment as embedded in our cultural, theological, and ethical contexts. Exactly the fact that we, through discernment and moral judgments and being pragmatically embedded in concrete cultural contexts, come to agreed-upon moral codes and the aposteriori affirmations of our seasoned 'moral laws', provide the pragmatic 'clout' and postfoundationalist justification for our moral convictions.

In another intriguing and constructive rereading of Schleiermacher, Kevin Hector has a made a theological argument for why Jesus' words and actions might be normative for our moral behaviour, an argument that closely converges with my own postfoundationalist reading of the grounding of moral behaviour in responsible discernment and evaluative judgment (cf. Hector 2008). In this constructive pneumatology Hector is looking for creative, 
bottom-up (my phrase) ways of talking about how the Holy Spirit works in our daily lives. Through a creative reading of Schleiermacher's pneumatology, Hector now wants to answer questions about how the Spirit 'indwells' us, how that indwelling 'writes God's laws on our hearts,' and how it in turn bears witness to Jesus Christ (Hector 2008:2). For Hector it is clear that Schleiermacher sees the Spirit as mediating Christ's new humanity to us, thereby extending Christ's redemptive work to us. If God is the pure activity of love, then in every instant of his life Jesus perfectly reproduces this activity as his own. And since Jesus is perfectly receptive to God's activity and spontaneously reproduces it as his own, Jesus is God incarnate, as we saw earlier. But what this now further implies is that we as believers must reproduce Jesus Christ's activity as our own, but we cannot do so on our own. However, our reproduction of Christ's activity is wholly dependent upon Christ, as is redemption, which can never be based on our initiative but only on that of God in Christ.

The problem, according to Schleiermacher, is that we do not have the direct personal connection that the disciples had with Jesus. In fact, we are connected to Jesus through his followers - our redemption is still through Jesus Christ alone, but we now have that not through Christ's physical presence but only through fellowship with him, through his followers, and thus through the church (Hector 2008:3). But how can the power of Jesus' influence ever be equated to that of believers through the centuries? That can only happen if the faith community's activity in some sense represents Christ's own activity so that the self-revelation of Christ is now mediated by those who preach him (Schleiermacher 1976:363) and in such a way that the activity that proceeds from him is essentially still his own (Schleiermacher 1976:490). And this presence of Jesus Christ in the community of believers, in the church, is the Holy Spirit. Another way of putting this: God mediates Jesus' activity to us through the Spirit's presence in the church and as such the Spirit mediates what Jesus said and did through the community, through which it then becomes ours (Hector 2008:4).

Schleiermacher's profound claim, then, is that we begin to understand Jesus' presence in our lives by understanding the Spirit's work when taking Jesus' disciples as a model. In the disciples we see the transformation we are trying to make sense of, the transformation in which Jesus' words and deeds became their own (Schleiermacher 
1976:529). As such the disciples were validated as competent judges of the beliefs and actions of others, and through thereby having internalised Jesus' instructions, the disciples could now not only reproduce Jesus' normative judgments, but in the ongoing history of the Christian faith their judgments would now be accepted by others as normative. In that sense restating not only Jesus' influence on the disciples and all believers since, we come to understand why we today should 'do as Jesus did'.

Because Schleiermacher focused on the normative dimension of Jesus' words and deeds, he is able to also account for our doing the same things in ever-changing circumstances (Hector 2008:8). What we have here, then, are socially mediated, experientially interpreted norms filtered through the history of the church and mediating to us aposteriori moral codes and normative judgments. For Schleiermacher God is present in Jesus, is present in the Spirit, and therefore he could make sense of the Spirit's work by talking about Jesus' normative judgments becoming our own as we learn them from those whose judgments have been recognised and critically evaluated as going on in the same way as his. This critical, postfoundationalist evaluation of the tradition as we stand in the tradition, is our only fallible way of judging whether or not certain beliefs and actions count as really following him, as qualifying to 'do what Jesus did'. In this way belief and interpretation fuse in the ongoing task of Christology and Ethics.

In this way Schleiermacher opens up a way of understanding the Spirit's work in terms of the way that Jesus' norms are mediated through an ongoing process of mutual, critical recognition and evaluation. This 'non-objective' grounding of the moral authority of Jesus through social and historical interpretation does not imply relativism and the idea that Jesus' words could mean whatever we take them to mean. On the contrary, a postfoundationalist position on Christ's normative sayings means exactly that in order to judge our own theological evaluations of these normative statements as plausibly correct, it necessarily implies that our current beliefs, actions, and judgments, are also constrained, but ultimately not determined, by previous networks of interpretations. Learning to follow Jesus, learning 'to do what Jesus did', is to learn to find the trajectory on which others preceded us in interpretation and action by internalising what we interpretatively recognise as normative for our current contexts (Hector 2008:14, 17). This ongoing, never- 
ending interpretative task of relating Christology to Ethics can inspire us with moral direction even as it fills us with epistemic humility.

\section{CONCLUSION}

Kevin Hector's creative interpretation of Schleiermacher's views on the social, cultural mediation of Jesus' normative statements might get an unexpected 'boost' from evolutionary theory. In a challenging essay, David Lahti (2004), in dealing with the evolution of morality and its adaptive significance, has found an intriguing and creative example for the adaptive role of moral evolution through cultural transmission in Jesus' Sermon on the Mount (Mt 5-7). Lahti (2004:140-143)argues that Jesus used his Sermon on the Mount as a way of challenging the traditional Hebrew understanding of 'culture', ancestry, and 'in-group' by turning away form notions of kin-relatedness to a new notion of relatedness based on shared values instead.

Lahti (2004:140) claims to have found some 105 moral statements in the Sermon in the Mount that refer to actions and/or attitudes that are good or bad, none of which encourage kin relatedness, tribal affiliation, or ethnicity. The remarkable fact that Lahti points to is how perfectly this fits with Darwin's own observations about the evolution of human culture. These teachings encourages this very change of attitude that Charles Darwin observed in human cultures, namely, a move away from a more primitive state of morality toward moral consideration for all persons regardless of relatedness (Darwin 1981:158-185). The real question, of course, is what normally are the causes of changes in a culture's typical moral attitudes? Morality originated, according to Darwin, as within-group cooperation arising in the context of between-group competition. Various evolutionary biologists are now stressing the point that Darwin also made, namely, that social selection tends to be the overwhelming determinant that makes human behaviours adaptive. Social selection, then, as a subset of natural selection, along with the cultural influence of social environments imply that certain changes in a society can lead to shifts in what kinds of behaviours tend to be adaptive. And here moral norms may provide a valuable mechanism for tracking the social environment (Lahti 2004:133). 
It is precisely against this background that a comparison of two social environments, Hebrew culture and the Palestine of Jesus' time, provide an explanation how a particular moral reform (that of Jesus) may have been an adaptive attitude adjustment. In this sense the moral teachings of Jesus realigned and modified earlier Jewish moral prescriptions, encouraging attitudes and actions that would be novel for its time. Strikingly, Jesus does create a division between groups in the Sermon on the Mount, but now they are seen as divisions based on moral differences rather than kinship, political, or ethic differences (Lahti 2004:142). This fits completely with the evolutionary view that the spreading of values in human communities can enlarge the group: the moral reform of Jesus as portrayed in the Sermon on the Mount thus reflects an adaptive adjustment to a new social environment, and lifts up a deliberate contrast between new norms being presented and the norms that would have been familiar to the Jewish people. But, as the repeated phrase 'You have heard....but I say to you' implies, for Jesus the law itself is still to be obeyed (Mt 5:19) even as traditionalism and innovation are now in tension. Lahti is thus correctly suggesting that these changes in moral emphasis allow us to see Jesus through the eyes of faith as well as through the eyes of evolutionary biology: it is not only in line with Darwin's understanding of the evolution of morality, but it also reveals that Jesus' life and teachings existed at a time when they would find maximal societal impact - first passed on by the in-group consisting of Jesus' disciples, later passed on by a vast history of ongoing critical evaluation and theological/ethical reinterpretation. I believe it is precisely this ongoing social mediation and cultural re-interpretation that would become the hallmark of what it means first to rethink the identity of Jesus, and then to follow Jesus in faith. Precisely by recognising that God's very being is incarnate, and thus present in Jesus' perfect consciousness, enables us to want to 'do as Jesus did,' and follow him in faith.

\section{Consulted literature}

Darwin, C 1981. The Descent of Man, and Selection in Relation to Sex. Princeton: Princeton University Press.

De Waal, F 2006. Primates and Philosophers: How Morality Evolved. Princeton: Princeton University Press.

Hare, J 2004. Is there an Evolutionary Foundation for Human Morality? in Clayton, P \& Schloss, J, Evolution and Ethics: Human Morality in 
Biological and Religious Perspective. Grand Rapids: Wm. B. Eerdmans, 187-203.

Hector, K. 2006. Actualism and Incarnation: The High Christology of Friedrich Schleiermacher, in International Journal of Systematic Theology 8(3), 307322.

-, 2008. The Mediation of Christ's Normative Spirit: A Constructive Reading of Schleiermacher's Pneumatology, Modern Theology 24(1), 1-22.

Joyce, R 2006. The Evolution of Morality. Cambridge, MA: The MIT Press.

Lahti, D C 2004. "You Have Heard...but I Tell You....": A Test of the Adaptive Significance of Moral Evolution, in Clayton, P \& Schloss, J, Evolution and Ethics: Human Morality in Biological and Religious Perspective Grand Rapids: Wm. B. Eerdmans, 132-150.

Schleiermacher, F 1976. The Christian Faith. Edinburgh: T \& T Clark.

Suchocki, M H 1994. The Fall to Violence: Original Sin in Relational Theology. New York: Continuum Publishing Company.

Wuketits, F M 1990. Evolutionary Epistemology and its Implications for Humankind. Albany: SUNY Press. 